\title{
Aarhus Green: A tetrafluoro-substituted derivative of fluorescein
}

\author{
Jeppe Holmehave, ${ }^{\dagger}$ Stephan K. Pedersen, ${ }^{\ddagger}$ Henrik H. Jensen, and Peter R. Ogilby* \\ Department of Chemistry, Aarhus University, Langelandsgade 140, Aarhus, DK-8000, Denmark \\ E-mail:progilby@chem.au.dk
}

Dedicated to Professor Michael Orfanopoulos on the occasion of his $67^{\text {th }}$ birthday

* These authors contributed equally to this work.

DOI: $\underline{\text { http://dx.doi.org/10.3998/ark.5550190.p009.011 }}$

\begin{abstract}
The synthesis and characterization of a $2^{\prime}, 4^{\prime}, 5^{\prime}, 7^{\prime}$-tetrafluorinated derivative of fluorescein, called Aarhus Green, is reported. As with related 2',7'-difluorinated compounds, tetrafluorination of the xanthene-derived moiety makes the more fluorescent anion accessible over a larger $\mathrm{pH}$ range. However, in contrast to a published report, we find that fluorination in the 4' and 5' positions does not appreciably decrease the fluorescence quantum yield, $\phi_{\mathrm{f}}$. Rather, Aarhus Green has a reasonably large $\phi_{\mathrm{f}}(0.79 \pm 0.04)$. Moreover, Aarhus Green does not efficiently sensitize the production of singlet oxygen and it is photostable. Thus, tetrafluorination of the xanthene moiety in fluorescein derivatives can be a useful tool in the development of fluorescent probes.
\end{abstract}

Keywords: Fluorescent probe, singlet oxygen, xanthene fluorination, fluorescein

\section{Introduction}

Fluorescein and derivatives of fluorescein are commonly used as fluorescent probes. ${ }^{1}$ In this regard, a key issue is the $\mathrm{pH}$ of the medium in which the molecule is dissolved. ${ }^{2-7}$ Specifically, the quantum efficiency of fluorescence, $\phi_{f}$, for the neutral molecule is small $(\sim 0.3-0.4)$. ${ }^{4,6}$ However, under alkaline conditions, where the xanthene-related chromophore/fluorophore exists as the anion, $\phi_{\mathrm{f}}$ is much larger (i.e., 0.92 for fluorescein). ${ }^{3,6,8}$ This point is illustrated in Figure 1. 


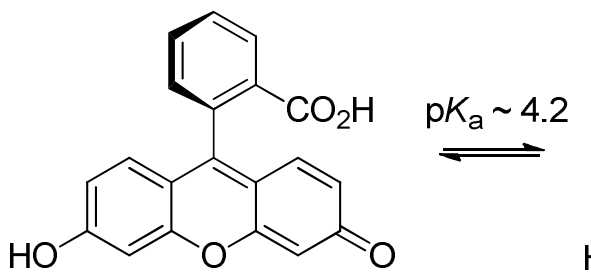

weakly fluorescent

good $\mathrm{O}_{2}\left(a^{1} \Delta_{g}\right)$ sensitizer

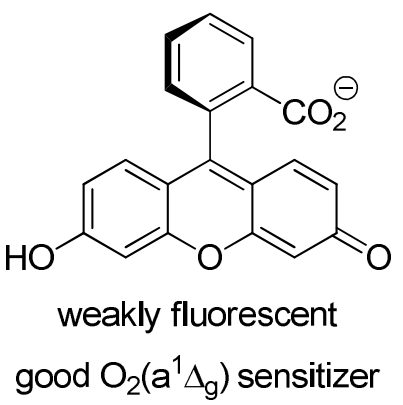<smiles>O=C([O-])c1ccccc1-c1c2ccc(=O)cc-2oc2cc(O)ccc12</smiles>

strongly fluorescent poor $\mathrm{O}_{2}\left(a^{1} \Delta_{g}\right)$ sensitizer

Figure 1. Illustration of the $\mathrm{pH}$-dependent changes in fluorescein that influence the quantum yields of fluorescence and photosensitized singlet oxygen, $\mathrm{O}_{2}\left(\mathrm{a}^{1} \Delta_{\mathrm{g}}\right)$, production. ${ }^{7}$ The principal chromophore/fluorophore/sensitizer in this molecule is the $\pi$ system of the xanthene-derived moiety.

In an attempt to render this fluorophore more useful under physiological conditions or more acidic conditions in general, it is acknowledged that adding electron-withdrawing halogen atoms to the xanthene-derived moiety reduces the $\mathrm{p} K_{\mathrm{a}}$ value. This has been explicitly shown, for example, with the difluorinated derivatives Pennsylvania Green ${ }^{4}$ and Oregon $\mathrm{Green}^{3}$ (see structures in Figure 2). Thus, the fluorinated derivatives become a more useful probe simply because they are strongly fluorescent over a larger $\mathrm{pH}$ range.<smiles></smiles>

Fluorescein<smiles>O=C(O)c1ccccc1-c1c2cc(F)c(=O)cc-2oc2cc(O)c(F)cc12</smiles>

Oregon Green<smiles>Cc1ccccc1-c1c2ccc(=O)cc-2oc2cc(O)ccc12</smiles>

Tokyo Green<smiles>O=C(O)c1ccc(-c2c3cc(F)c(=O)cc-3oc3cc(O)c(F)cc23)c(C(=O)O)c1</smiles>

5(6)-carboxy-Oregon Green<smiles>Cc1ccccc1-c1c2cc(F)c(=O)cc-2oc2cc(O)c(F)cc12</smiles>

Pennsylvania Green<smiles>O=C(O)c1ccccc1-c1c2cc(F)c(=O)c(F)c-2oc2c(F)c(O)c(F)cc12</smiles>

4',5'-difluoro-Oregon Green

Figure 2. Structures of selected fluorescein derivatives, shown as the neutral species. The accepted numbering system for these molecules is shown on the structure of fluorescein in the upper left corner. 
It has also been shown that, relative to the neutral species, the anion of the xanthene moiety in such fluorescein derivatives is a poor photosensitizer for the production of singlet molecular oxygen, $\mathrm{O}_{2}\left(\mathrm{a}^{1} \Delta_{\mathrm{g}}\right)^{7}$ This is a desirable attribute in many applications; one would want a benign probe that does not generate reactive oxygen species that could perturb the system under study. Correlated to this is the fact that the anion is generally also more stable than the corresponding neutral compound upon prolonged irradiation (i.e., because it does not make much $\mathrm{O}_{2}\left(\mathrm{a}^{1} \Delta_{\mathrm{g}}\right)$ it does not photobleach as readily). ${ }^{3,7}$

As seen in Figure 2, Pennsylvania Green and Oregon Green are fluorinated in the 2' and 7' positions of the xanthene moiety. This is important in the context of work published by Sun $e t$ $a l .{ }^{3}$ Specifically, they indicated that fluorination in the 2' and 7' positions had little or no effect on the quantum efficiency of fluorescence relative to the fluorescein dianion $\left(\phi_{\mathrm{f}}=0.92\right)$, whereas fluorination in the 4' and 5' positions decreased the fluorescence quantum yield appreciably.

As a consequence of some recent work on the development of a fluorescent sensor for $\mathrm{O}_{2}\left(\mathrm{a}^{1} \Delta_{\mathrm{g}}\right){ }^{7}$ called Aarhus Sensor Green, we set out to investigate properties of 2',4',5',7'tetrafluorinated derivatives of fluorescein. In contrast to Sun et al., ${ }^{3}$ we found that fluorination in the 4' and 5' positions of the xanthene moiety did not have an adverse effect on the fluorescence quantum yield. Our observations were made using the compounds shown in Figure 3. Following the tradition of nomenclature in this field (e.g., Tokyo, Pennsylvania, and Oregon Greens), we call our parent tetrafluorinated derivative Aarhus Green.<smiles>Cc1ccccc1-c1c2cc(F)c(=O)c(F)c-2oc2c(F)c(O)c(F)cc12</smiles>

Aarhus Green<smiles>Cc1cc(C(=O)O)ccc1-c1c2cc(F)c(=O)c(F)c-2oc2c(F)c(O)c(F)cc12</smiles>

5-carboxy-Aarhus Green

Figure 3. Structures of Aarhus Green and 5-carboxy-Aarhus Green, shown as the neutral species.

Here, we report the synthesis of Aarhus Green and the 5-carboxy derivative of Aarhus Green (Figure 3). We also present the results of experiments used to characterize the photophysical and photochemical properties of these compounds. We conclude that tetrafluorination of the xanthene moiety in a fluorescein derivative does not necessarily have adverse effects. Indeed, tetrafluorination can have distinct advantages with respect to difluorinated derivatives and, as such, can be a useful tool in the development of fluorescent probes. 


\section{Results and Discussion}

\section{Synthesis of Aarhus Green}

The approach used to prepare the precursor of the tetrafluorinated xanthene core in Aarhus Green is shown in Scheme 1. Although this approach is based on published procedures, ${ }^{3,4,7}$ compounds $\mathbf{4}$ and $\mathbf{5}$ are, to our knowledge, novel.

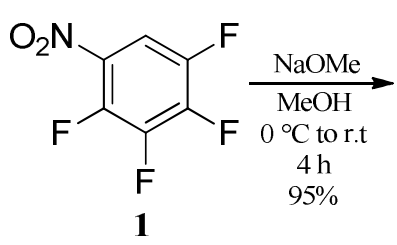

1<smiles>COc1c(N)cc(F)c(OC)c1F</smiles><smiles>COc1c(F)cc(I)c(OC)c1F</smiles><smiles>COc1c(F)c(F)c(C(=O)c2cc(F)c(OC)c(OC)c2OC)c(OC)c1F</smiles>

Scheme 1. General synthetic scheme to prepare the precursor of the tetrafluorinated xanthene moiety used in the preparation of both Aarhus Green and 5-carboxy-Aarhus Green.

For the addition of the aryl group to compound $\mathbf{5}$, we modified and optimized a procedure originally published by Mottram, et al. ${ }^{4}$ (Scheme 2). The subsequent ring closure to make the xanthene-related moiety was achieved using a slight modification of a procedure published by Yang, et al..$^{9}$ In this latter case, we prefer the more easily-handled $\mathrm{HBr} / \mathrm{AcOH}$ instead of $\mathrm{BBr}_{3}$ for the ring closure (Scheme 2) despite the need for several additions of $\mathrm{HBr} / \mathrm{AcOH}$ (possibly due to leakage of $\mathrm{HBr}$ from the reaction vessel).

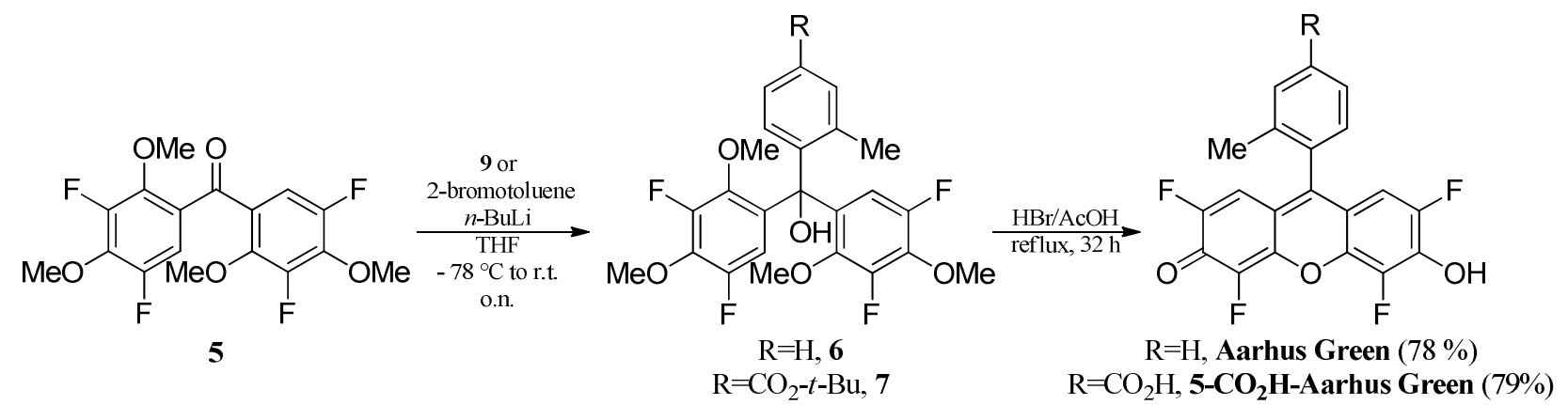

Scheme 2. Synthetic scheme to add the pendant aryl group and construct the xanthene-related core in both Aarhus Green and 5-carboxy-Aarhus Green. For the preparation of Aarhus Green, 2- 
bromotoluene was used in the first step, whereas compound 9 was used for the preparation of 5carboxy-Aarhus Green.

\section{Synthesis of 5-carboxy-Aarhus Green}

To render a given fluorescent probe more useful, it can be helpful to append a group that facilitates further functionalization reactions (e.g., attach the probe to a protein). For these fluorescein derivatives, a carboxyl group often works well. ${ }^{4,10}$ As such, we set out to also prepare 5-carboxy-Aarhus Green.

To this end, the procedure shown in Scheme 2 was also used. However, to add the properly functionalized pendant aryl group, the ester 9 shown in Scheme 3 was used instead of 2-bromotoluene used in the preparation of Aarhus Green. In the ring closure reaction shown in Scheme 2, this ester is hydrolyzed to yield the desired carboxy group.

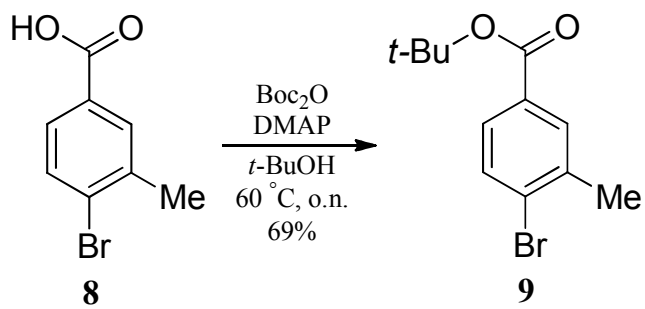

Scheme 3. Procedure to prepare the pendant aryl group used for the synthesis of 5-carboxyAarhus Green. ${ }^{11}$

It is important to note that, using this procedure, we only obtain the 5-carboxy isomer. In the approach used by Sun et $a l^{3}{ }^{3}$ to prepare the corresponding carboxylated 4',5'-difluoro Oregon Greens, a mixture of the 5- and 6-carboxy isomers are obtained (Figure 2 and Scheme 4).<smiles></smiles><smiles>O=C(O)c1ccc(-c2c3cc(F)c(=O)c(F)c-3oc3c(F)c(O)c(F)cc23)c(C(=O)O)c1</smiles>

Mixture of the 5- and 6-carboxy isomers

Scheme 4. Illustration of the process used by Sun et al. ${ }^{3}$ to make the carboxylated 4',5'-difluoroOregon Green that results in a mixture of the 5- and 6-carboxy isomers.

\section{Photophysical and photochemical properties: absorption and emission spectra}

The absorption and emission spectra of Aarhus Green are shown in Figure 4. The data obtained are consistent with those from other fluorinated derivatives of fluorescein. ${ }^{3}$ 


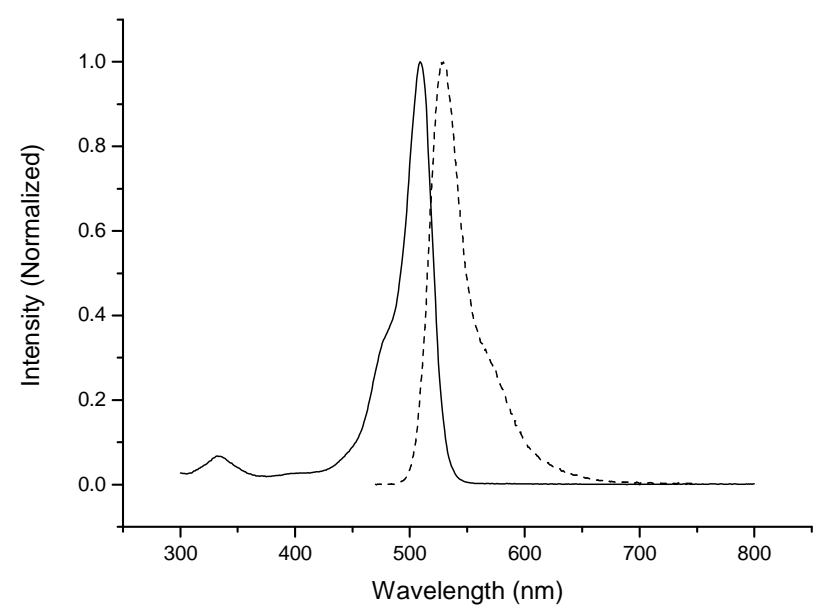

Figure 4. Absorption (solid line) and emission (dashed line) spectra of Aarhus Green recorded in a phosphate-buffered aqueous solution ( $\mathrm{pH} \mathrm{7.4).} \mathrm{The} \lambda_{\max }$ of the absorption band is $509 \mathrm{~nm}$ and the $\lambda_{\max }$ of the emission band is $529 \mathrm{~nm}$. The corresponding spectra of 5-carboxy-Aarhus Green are essentially identical, with an absorption $\lambda_{\max }$ of $511 \mathrm{~nm}$ and an emission $\lambda_{\max }$ of $532 \mathrm{~nm}$.

\section{Photophysical and photochemical properties: fluorescence quantum yields}

Quantum yields of fluorescence were determined for selected fluorescein derivatives at $\mathrm{pH} 7.4$ (i.e., phosphate buffered solutions) and at $\mathrm{pH}$ 5.0. These experiments were performed using an alkaline $\mathrm{H}_{2} \mathrm{O}$-based solution of fluorescein as the standard with $\phi_{\mathrm{f}}=0.92 \pm 0.02 .{ }^{8}$ The data obtained are shown in Table 1.

Table 1. Quantum yields of fluorescence, $\phi_{\mathrm{f}}$, and $\mathrm{O}_{2}\left(\mathrm{a}^{1} \Delta_{\mathrm{g}}\right)$ production, $\phi_{\Delta}$, determined at different $\mathrm{pH}$ values for several fluorescein derivatives ${ }^{\mathrm{a}}$

\begin{tabular}{ccccc}
\hline Compound & $\begin{array}{c}\phi_{\mathrm{r}} \\
\mathbf{p H ~ 7 . 4}\end{array}$ & $\begin{array}{c}\phi_{\mathrm{F}} \\
\mathbf{p H ~ 5 . 0}\end{array}$ & $\begin{array}{c}\phi_{\Delta} \\
\mathbf{p H ~ 7 . 4}\end{array}$ & $\begin{array}{c}\phi_{\Delta} \\
\mathbf{p H ~ 4 . 7}\end{array}$ \\
\hline Fluorescein & $0.92^{\mathrm{b}}$ & & $0.14^{\mathrm{c}}$ & \\
Pennsylvania Green & $0.91^{\mathrm{d}}$ & & 0.05 & \\
5(6)-carboxy-4',5'-difluorofluorescein & $\mathbf{0 . 4 3}^{\mathrm{e}}$ & & & \\
5(6)-carboxy-4',5'-difluoro-Oregon Green & $\mathbf{0 . 5 9}^{\mathrm{e}}$ & & & \\
5(6)-carboxy-Oregon Green & $0.92 / 0.92^{\mathrm{e}}$ & 0.80 & 0.027 & 0.26 \\
4',5'-difluoro-Oregon Green & $\mathbf{0 . 9 5}$ & 0.75 & 0.059 & 0.027 \\
Aarhus Green & $\mathbf{0 . 7 9}$ & 0.79 & 0.095 & 0.045 \\
5-carboxy-Aarhus Green & $\mathbf{0 . 7 7}$ & 0.76 & 0.092 & 0.037 \\
\hline
\end{tabular}

${ }^{\mathrm{a}}$ Errors on all quantum yields determined in this study are $\sim \pm 5 \%$ of the value shown. ${ }^{\mathrm{b}}$ Value reported by Sun, et al. ${ }^{3}$ and Magde, et al. ${ }^{8 \mathrm{c}}$ From Pedersen, et al. ${ }^{7 \mathrm{~d}}$ From Mottram, et al..$^{10}$ ${ }^{\mathrm{e}}$ From Sun, et al., ${ }^{3}$ determined at $\mathrm{pH} 9$. 
Let us first consider the data recorded under more alkaline conditions. It is clear that for the 2',7'-difluoro substituted compound 5(6)-carboxy-Oregon Green, data we recorded are consistent with the data of Sun et al. ${ }^{3}$ In short, we both agree that this compound is highly fluorescent with $\phi_{\mathrm{f}}=0.92$.

However, our results differ from those of Sun et al., ${ }^{3}$ when considering the 4',5'difluorinated and 2',4',5',7'-tetrafluorinated derivatives. To emphasize these data in particular, they are presented in bold font in Table 1. The data recorded by Sun et al., indicate that when the xanthene moiety is fluorinated in the 4' and 5' positions, the quantum yield of fluorescence is comparatively small ( 0.43 and 0.59 for the examples shown in Table 1$)$. Indeed, these results contributed to their overall conclusion that fluorination in the 4' and 5' positions adversely influences the fluorescence yield. It is also interesting to note that their data were recorded at the more alkaline $\mathrm{pH}$ value of 9 which should drive the equilibrium shown in Figure 1 further to the more fluorescent anionic forms. In contrast, data we recorded from compounds fluorinated in the 4' and 5' position all have much larger quantum yields of fluorescence than the corresponding compounds of Sun, et al. For example, Aarhus Green has a quantum yield of $0.79 \pm 0.04$ and 4',5'-difluoro-Oregon Green (i.e., tetrafluorofluorescein) has a quantum yield of $0.95 \pm 0.05$. Admittedly, we did not examine the exact same compounds studied by Sun et al. Specifically, the dicarboxylated pendant phenyl group in the compounds they studied might contribute to the smaller values of $\phi_{\mathrm{f}}$ that they report. Nevertheless, our data certainly indicate that 4' and 5' fluorination on the xanthene moiety does not always have an adverse effect on the fluorescence quantum yield of a fluorescein derivative.

The data in Table 1 also appear to show one arguably expected advantage of using a tetrafluorinated derivative. The fluorescence quantum yields of both Aarhus Green and 5-carboxy-Aarhus Green do not decrease as the $\mathrm{pH}$ is decreased from 7.4 to 5. This presumably reflects the fact that the four electron withdrawing fluorine atoms further stabilize the xanthenederived anion reducing the $\mathrm{p} K_{\mathrm{a}}$ value of the compound. On the other hand, the fluorescence quantum yield of 5(6)-carboxy-Oregon Green, which is a difluorinated compound, decreases slightly as the $\mathrm{pH}$ is reduced to a value of 5 . These points are supported by titration curves shown in Figure 5. A complicating caveat here is that we also observe a slight decrease in the fluorescence quantum yield for 4',5'-difluoro-Oregon Green. To account for this observation, we can only speculate that the ortho-substituted carboxyl group in the pendant aryl group of the Oregon Greens imparts unique behavior that sets them apart from the Aarhus Greens that have a methyl group in this same position. 


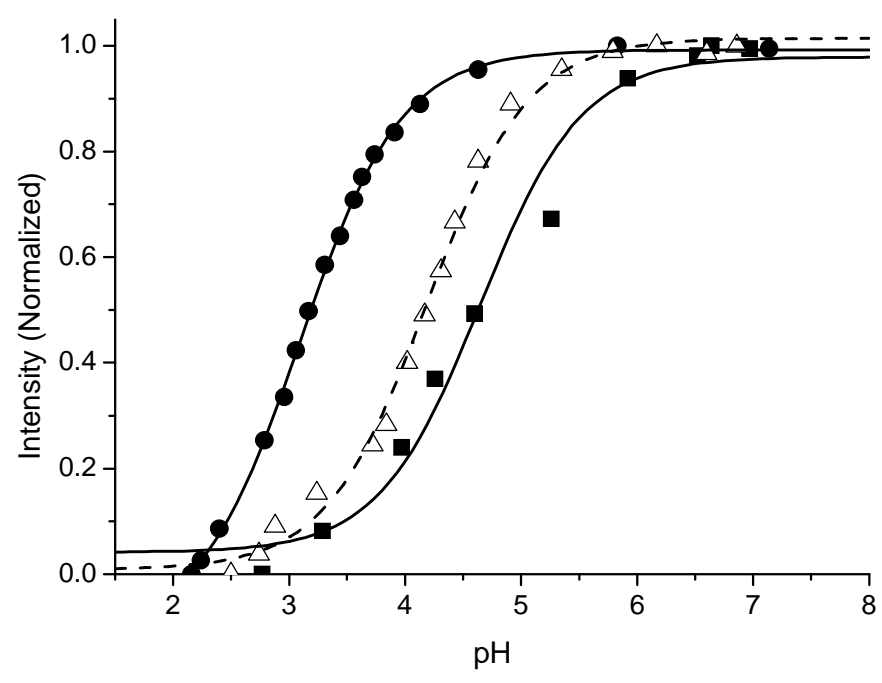

Figure 5. Plots of the normalized fluorescence intensity, $I$, against solution $\mathrm{pH}$ for Aarhus Green (filled circles), 5(6)-carboxy-Oregon Green (open triangles), and Pennsylvania Green (filled squares). The solid lines were obtained using a double-reciprocal plot of $I$ against $\mathrm{pH}$ and yield $\mathrm{p} K_{\mathrm{a}}$ values of $3.1 \pm 0.1,4.2 \pm 0.1$, and $4.7 \pm 0.1$ for these three compounds, respectively.

\section{Photophysical and photochemical properties: singlet oxygen quantum yields}

In a previous study, we demonstrated that the cumulative addition of more fluorine atoms to the xanthene chromophore in fluorescein derivatives also influences the quantum yield of sensitized $\mathrm{O}_{2}\left(\mathrm{a}^{1} \Delta_{\mathrm{g}}\right)$ production, $\phi_{\Delta} .{ }^{7}$ In short, by shifting the $\mathrm{p} K_{\mathrm{a}}$ to smaller values, one favors the formation of the xanthene-derived anion over a larger $\mathrm{pH}$ range (see Figure 1) which, in turn, is a poorer $\mathrm{O}_{2}\left(\mathrm{a}^{1} \Delta_{\mathrm{g}}\right)$ sensitizer than the neutral form of the chromophore. ${ }^{7}$

The data shown in Table 1 are also consistent with the model. Specifically, 5(6)-carboxyOregon Green, which is a difluorinated compound, sensitizes the production of $\mathrm{O}_{2}\left(\mathrm{a}^{1} \Delta_{\mathrm{g}}\right)$ with a yield of 0.26 at $\mathrm{pH} 4.7$. However, the three tetrafluorinated compounds examined in this study all have yields of sensitized $\mathrm{O}_{2}\left(\mathrm{a}^{1} \Delta_{\mathrm{g}}\right)$ production that are much smaller at $\mathrm{pH}$ 4.7.

\section{Photophysical and photochemical properties: photobleaching}

Another important parameter of a molecule used as a fluorescent probe is the extent to which it degrades (i.e., bleaches) upon prolonged irradiation. ${ }^{1,12}$ Although many events can contribute to this potentially complicated process, there is no doubt that the photobleaching process is generally exacerbated in oxygen-containing solutions and under conditions in which an excited state of the probe can sensitize the production of $\mathrm{O}_{2}\left(\mathrm{a}^{1} \Delta_{\mathrm{g}}\right)$.

In an attempt to quantify the relative susceptibility of selected fluorescein derivatives, including Aarhus Green and 5-carboxy-Aarhus Green, to photobleaching, we used a technique published by Sun et al. ${ }^{3}$ in which percent changes in the fluorescence intensity of the compound were monitored as a function of elapsed irradiation time. The resultant data, shown in Table 2, 
indicate that fluorination indeed also imparts greater photostability to the fluorescein derivative. This conclusion is consistent with those of Sun et al., ${ }^{3}$ and Mottram et al. ${ }^{4}$

Table 2. Parameters that quantify the susceptibility of selected fluorescein derivatives to photobleaching in air-saturated aqueous solutions at $\mathrm{pH} 7.4$

\begin{tabular}{cc} 
Compound & $\begin{array}{c}\text { Bleaching Parameter }^{\mathbf{a}} \\
\text { pH 7.4 }\end{array}$ \\
\hline Fluorescein & 25 \\
5(6)-carboxy-Oregon Green & 12 \\
4',5'-difluoro-Oregon Green & 7 \\
Aarhus Green & 8 \\
5-carboxy-Aarhus Green & 10 \\
\hline
\end{tabular}

${ }^{\text {a }}$ Percentage decrease of fluorescence intensity, measured at the $\lambda_{\max }$ of emission, upon 30 min of irradiation in a fluorimeter at the $\lambda_{\max }$ of the compound's absorption spectrum. In all cases, solutions were prepared to have an absorbance of 0.1 at $\lambda_{\max }$.

\section{Conclusions}

We have prepared and characterized new fluorinated derivatives of fluorescein that have desirable properties for use as a fluorescent probe. Most of these properties reflect the fact that the xanthene-derived chromophore/fluorophore has been substituted with four fluorine atoms. Moreover, we demonstrate that the placement of fluorine atoms at the 4' and 5' positions on the xanthene moiety in the fluorescein derivative does not necessarily have an adverse effect on the quantum yield of fluorescence. Given the properties of Aarhus Green reported herein, it could also serve as a useful fluorescence quantum yield standard over a large $\mathrm{pH}$ range.

\section{Experimental Section}

General. The instrumentation and approaches used to quantify fluorescence quantum yields and $\mathrm{O}_{2}\left(\mathrm{a}^{1} \Delta_{\mathrm{g}}\right)$ quantum yields have been reported previously. ${ }^{7}$

The general methods used for the preparation, isolation, purification and characterization of our compounds have likewise been reported previously. ${ }^{7}$ Briefly, air- and moisture sensitive reactions were conducted in flame-dried glassware under an atmosphere of argon. Anhydrous solvents were dried over aluminum oxide and dispensed from a solvent purification system. All other chemicals were used as received without further purification. Flash chromatography was carried out on silica gel 60 (230-400 mesh). TLC analysis was conducted on silica gel coated aluminum foil (Kieselgel 60 F254). Microwave heated reactions were performed using a Biotage 
Initiator 2.0 microwave synthesizer. The ${ }^{1} \mathrm{H},{ }^{13} \mathrm{C}$ and ${ }^{19} \mathrm{~F}$ NMR spectra were recorded at 400,100 and $376 \mathrm{MHz}$, respectively. The chemical shifts for the NMR spectra are reported in ppm relative to the solvent residual peak. HRMS were performed on a LC TOF (ES) instrument. The synthesis and characterization of 1,3-difluoro-2,4-dimethoxy-5-nitrobenzene (2) and 3,5difluoro-2,4-dimethoxyaniline (3) are published elsewhere. ${ }^{3,7,13}$

1,3-Difluoro-5-iodo-2,4-dimethoxybenzene (4). 3,5-Difluoro-2,4-dimethoxyaniline (3) (4.13 g, $21.8 \mathrm{mmol})$ was added to a stirred solution of aqueous $\mathrm{HCl}(0.3 \mathrm{M}, 72 \mathrm{~mL})$ kept at $4{ }^{\circ} \mathrm{C}$. The stirred mixture was treated with a cold sodium nitrite solution $(2.50 \mathrm{~g}, 36.2 \mathrm{mmol})$ in water (49 $\mathrm{mL})$. After stirring for $30 \mathrm{~min}$, sodium iodide $(10.85 \mathrm{~g}, 72.4 \mathrm{mmol})$ was added slowly. The reaction mixture was slowly allowed to reach room temperature overnight. The reaction was neutralized with $1 \mathrm{M} \mathrm{NaOH}$ and the aqueous layers were extracted with dichloromethane, and the combined organic fractions were dried $\left(\mathrm{Na}_{2} \mathrm{SO}_{4}\right)$, and solvents removed in vacuo. The obtained residue was purified with flash column chromatography (pentane/EtOAc, 7:3) giving pure 4 as an oil $(4.56 \mathrm{~g}, 69 \%) . R_{\mathrm{f}}$ (pentane/EtOAc, 7:3) $=0.30 .{ }^{1} \mathrm{H} \mathrm{NMR}\left(400 \mathrm{MHz}, \mathrm{CDCl}_{3}\right): \delta_{\mathrm{H}}$ ppm 7.34-7.25 (m, 1H), 4.03-3.97 (m, 3H), 3.91-3.86 (m, 3H). $\left.{ }^{19} \mathrm{~F} \mathrm{NMR} \mathrm{(377} \mathrm{MHz,} \mathrm{CDCl}_{3}\right): \delta_{\mathrm{F}}$ ppm 132.8 (s, 1F), 141.5 (s, 1F). ${ }^{13} \mathrm{C}$ NMR $\left(100 \mathrm{MHz}, \mathrm{CDCl}_{3}\right): \delta_{\mathrm{C}} \mathrm{ppm} 153.2(\mathrm{~m}), 150.7(\mathrm{~m})$, $150.0(\mathrm{~m}), 147.5(\mathrm{~m}), 145.5(\mathrm{~m}), 138.0(\mathrm{~m}), 120.2$ (dd, J 22.3, $3.3 \mathrm{~Hz}), 81.4(\mathrm{~d}, J 9.3 \mathrm{~Hz}), 62.0$ (m), $61.6(\mathrm{~m})$. $\mathrm{HRMS} \mathrm{C}_{8} \mathrm{H}_{7} \mathrm{~F}_{2} \mathrm{IO}_{2}[\mathrm{M}+\mathrm{H}]^{+}$; calculated 300.9537, found 300.9536 .

Bis(3,5-difluoro-2,4-dimethoxyphenyl)methanone (5). 1,3-Difluoro-5-iodo-2,4-dimethoxybenzene (4) (300 $\mathrm{mg}, 1.00 \mathrm{mmol}$ ) was added to a microwave reaction vessel and dissolved in dry MeCN (4.2 mL). Upon addition of dicobalt octacarbonyl (228 mg, $0.667 \mathrm{mmol}$ ) bubbling was observed. The vessel was sealed and put in a microwave synthesizer. The synthesizer was set to a temperature of $250{ }^{\circ} \mathrm{C}$ and the time to 2 minutes. The irradiation was started and subsequently stopped after the temperature reached $130{ }^{\circ} \mathrm{C}$, approximately 20 seconds. After cooling to room temperature, the reaction mixture was filtered through Celite, solvents removed in vacuo and the residue was purified by flash column chromatography (dichloromethane/pentane, 1:1). 5 was obtained as a clear oil $(307 \mathrm{mg}, 82 \%) . R_{\mathrm{f}}$ (dichloromethane/pentane, 1:1) $=0.60 .{ }^{1} \mathrm{H}$ NMR $(400$ $\left.\mathrm{MHz}, \mathrm{CDCl}_{3}\right): \delta_{\mathrm{H}} \mathrm{ppm} 7.08(\mathrm{dd}, J 11.1,2.2 \mathrm{~Hz}, 2 \mathrm{H}), 4.10(\mathrm{~s}, 6 \mathrm{H}), 3.70(\mathrm{~d}, J 1.5 \mathrm{~Hz}, 6 \mathrm{H}) .{ }^{19} \mathrm{~F}$ NMR (377 MHz, $\left.\mathrm{CDCl}_{3}\right): \delta_{\mathrm{F}} \mathrm{ppm} 133.8(\mathrm{~m}, 2 \mathrm{~F}), 144.4(\mathrm{~m}, 2 \mathrm{~F}) .{ }^{13} \mathrm{C} \mathrm{NMR}\left(100 \mathrm{MHz}, \mathrm{CDCl}_{3}\right): \delta_{\mathrm{C}}$ ppm 189.9, 150.5 (dd, $J 245.5,4.3 \mathrm{~Hz}), 148.6$ (dd, $J$ 148.6, $5.7 \mathrm{~Hz}), 144.4$ (dd, $J$ 10.8, $3.3 \mathrm{~Hz}$ ), $140.6(\mathrm{dd}, J 14.4,12.1 \mathrm{~Hz}), 127.6(\mathrm{~d}, J 5.8 \mathrm{~Hz}), 111.4(\mathrm{dd}, J 21.7,3.4 \mathrm{~Hz}), 62.2$ (d, $J 5.8 \mathrm{~Hz})$, $61.8(\mathrm{~J} 4.0 \mathrm{~Hz}) \mathrm{HRMS} \mathrm{C}{ }_{17} \mathrm{H}_{14} \mathrm{~F}_{4} \mathrm{O}_{5}[\mathrm{M}+\mathrm{H}]^{+}$; calculated 375.0856, found 375.0850.

2,4,5,7-Tetrafluoro-6-hydroxy-9-(o-tolyl)-3H-xanthen-3-one (Aarhus Green). A round bottomed flask was flame dried and flushed with argon. 2-Bromotoluene (129 $\mu \mathrm{L}, 1.07 \mathrm{mmol})$ which was dissolved in dry THF $(5.3 \mathrm{~mL})$ was added to the flask under an argon atmosphere and cooled in a dry ice/acetone bath. $n$-BuLi $(1.6 \mathrm{M}$ in hexane, $668 \mu \mathrm{L}, 1.07 \mathrm{mmol})$ was slowly added to the cooled reaction mixture. Upon stirring for $1 \mathrm{~h}$ a solution of 5 (40 mg, $0.107 \mathrm{mmol}$ ) dissolved in dry THF $(0.5 \mathrm{~mL})$ was added slowly. The reaction was allowed to reach room temperature overnight, upon which it was quenched with slow addition of water. The aqueous 
layer was extracted three times with dichloromethane, and the combined organic fractions were dried $\left(\mathrm{MgSO}_{4}\right)$ and solvents removed in vacuo. The obtained residue, containing 6 (verified by HRMS), was added to a round bottomed flask to which a solution of $\mathrm{HBr}(6 \mathrm{~mL}, 33 \mathrm{wt} \%$ in acetic acid) was cautiously added. A reflux condenser was fitted and the reaction was heated to reflux. Every approximately $6^{\text {th }}$ hour additional $\mathrm{HBr}(1 \mathrm{~mL}, 33 \mathrm{wt} \%$ in acetic acid $)$ was added. After $32 \mathrm{~h}$ the reaction mixture was cooled to room temperature. Water was cautiously added and the aqueous layer was extracted three times with dichloromethane, dried $\left(\mathrm{MgSO}_{4}\right)$ and the solvents were removed in vacuo. The obtained solid was purified using flash column chromatography (chloroform/methanol/acetic acid, 17:3:1) to give Aarhus Green as a dark red solid (31 mg, 78\%). $R_{\mathrm{f}}$ (chloroform/methanol/acetic acid, 17:3:1) $=0.30 .{ }^{1} \mathrm{H}$ NMR $(400 \mathrm{MHz}$, methanol- $\left.d_{4}\right): \delta_{\mathrm{H}}$ ppm $7.57-7.41(\mathrm{~m}, 3 \mathrm{H}), 7.23(\mathrm{~d}, J 7.4 \mathrm{~Hz}, 1 \mathrm{H}), 6.56(\mathrm{~d}, J 11.0 \mathrm{~Hz}, 2 \mathrm{H}), 2.06$ (s, 3H). ${ }^{19}$ F NMR (377 MHz, methanol- $\left.d_{4}\right): 132.3(\mathrm{dd}, J 18.5,11.3 \mathrm{~Hz}, 2 \mathrm{~F}), 163.5(\mathrm{~d}, J 18.6 \mathrm{~Hz}$, 2F). ${ }^{13} \mathrm{C}$ NMR (100 MHz, methanol- $\left.d_{4}\right): 157.5(\mathrm{~m}), 155.0(\mathrm{~m}), 154.9(\mathrm{~m}), 144.9(\mathrm{~m}), 144.8(\mathrm{~m})$, $143.8(\mathrm{~m}), 142.5(\mathrm{~m}), 142.4(\mathrm{~m}), 137.3,133.6,131.8,131.1,130.1,127.2,108.7$ (d, J 22.2 Hz), 19.5. HRMS $\mathrm{C}_{20} \mathrm{H}_{10} \mathrm{~F}_{4} \mathrm{O}_{3}[\mathrm{M}+\mathrm{H}]^{+}$; calculated 375.0642, found 375.0644.

tert-Butyl 4-bromo-3-methylbenzoate (9). DMAP (0.170 g, $1.395 \mathrm{mmol})$ and Boc-anhydride $(1.02 \mathrm{~g}, 4.65 \mathrm{mmol})$ were added to a stirred suspension of $8(1.00 \mathrm{~g}, 4.65 \mathrm{mmol})$ in $t$-BuOH (23 $\mathrm{mL}$ ). The suspension was heated to $60^{\circ} \mathrm{C}$, upon which all starting materials were solubilized and the evolution of gas was observed. After being stirred overnight the reaction was cooled to room temperature. The reaction was diluted with water and extracted three times with dichloromethane. The organic fractions were combined, dried $\left(\mathrm{MgSO}_{4}\right)$ and the solvents were removed by rotatory evaporation to give a clear colorless oil. Purification by flash column chromatography (pentane/dichloromethane, 9:1) afforded $9(0.870 \mathrm{~g}, 69 \%)$ as a colorless oil. Product structure and purity were verified by HRMS, ${ }^{1} \mathrm{H},{ }^{19} \mathrm{~F}$ and ${ }^{13} \mathrm{C} \mathrm{NMR}$, and the data were found to be in accord with what has previously been reported for this compound. ${ }^{11}$

3-Methyl-4-(2,4,5,7-tetrafluoro-6-hydroxy-3-oxo-3H-xanthen-9-yl)benzoic acid (5-CO $\mathrm{CO}_{2} \mathrm{H}$ Aarhus Green). Compound 9 (181 mg, $0.668 \mathrm{mmol})$ was dissolved in dry THF (10 mL) in a flame dried flask under an argon atmosphere and cooled in a dry ice/acetone bath. $n$-BuLi (1.6 M in hexanes, $0.420 \mathrm{~mL}, 0.668 \mathrm{mmol}$ ) was added dropwise using a syringe. The reaction was stirred for $30 \mathrm{~min}$ at the same temperature. $5(50 \mathrm{mg}, 0.134 \mathrm{mmol})$ dissolved in THF (3 mL) was added dropwise and the reaction was allowed to reach room temperature overnight. The reaction was quenched by slow addition of saturated $\mathrm{NH}_{4} \mathrm{Cl}$, and $\mathrm{THF}$ was removed under reduced pressure. The aqueous layer was extracted 3 times with dichloromethane. The organic fractions were combined and the solvents removed under reduced pressure. The crude mixture was purified by flash column chromatography (pentane/EtOAc, 19:1) giving a residue containing 7 (verified by HRMS). The residue was added to a round bottomed flask to which a solution of $\mathrm{HBr}(6 \mathrm{~mL}, 33 \mathrm{wt} \%$ in acetic acid) was cautiously added. A reflux condenser was fitted and the reaction was heated to reflux. Every approximately $6^{\text {th }}$ hour an additional $\mathrm{HBr}(1 \mathrm{~mL}, 33 \mathrm{wt} \%$ in acetic acid) was added. After $32 \mathrm{~h}$ the reaction was cooled to room temperature. Water was cautiously added and the aqueous layer was extracted three times with dichloromethane, dried 
over $\mathrm{MgSO}_{4}$. The obtained solid was purified using flash column chromatography (chloroform/methanol/acetic acid, 189:10:1) to give 5-CO $\mathbf{C O}_{2} \mathbf{H}$-Aarhus Green (44 $\mathrm{mg}, 79 \%$ ) as a red solid. $R_{\mathrm{f}}$ (chloroform/MeOH/AcOH, 100:25:1) $=0.30 .{ }^{1} \mathrm{H}$ NMR $\left(400 \mathrm{MHz}\right.$, methanol- $\left.d_{4}\right): \delta_{\mathrm{H}}$ ppm $8.16(\mathrm{~s}, 1 \mathrm{H}), 8.10 .(\mathrm{d}, J 8.0 \mathrm{~Hz}, 1 \mathrm{H}), 7.42(\mathrm{~d}, J 7.9 \mathrm{~Hz}, 1 \mathrm{H}), 6.70(\mathrm{~d}, J 10.4 \mathrm{~Hz}, 2 \mathrm{H}), 2.15$ (s, $3 \mathrm{H}) .{ }^{19} \mathrm{~F}$ NMR $\left(377 \mathrm{MHz}, \mathrm{D}_{2} \mathrm{O}\right): \delta_{\mathrm{F}} \mathrm{ppm} 131.1(\mathrm{dd}, J 17.2,11.3 \mathrm{~Hz}, 2 \mathrm{~F}), 162.0(\mathrm{~d}, J 17.2 \mathrm{~Hz}, 2 \mathrm{~F})$ ${ }^{13} \mathrm{C}$ NMR (100 MHz, methanol- $\left.d_{4}\right)$ : 168.9, 155.5, 153.6, 152.9, 143.6, 143.5, 142.6, 141.2, 138.3, 137.1, 134.0, 133.1, 130.7, 128.6, 114.6, 114.5, 109.5, 109.3, 19.5. HRMS $\mathrm{C}_{21} \mathrm{H}_{10} \mathrm{~F}_{4} \mathrm{O}_{5}[\mathrm{M}+\mathrm{H}]^{+}$; calculated 419.0543, found 419.0437 .

5(6)-Carboxy-Oregon Green and 4',5'-difluoro Oregon Green were prepared using the procedure of Sun $e t a l .^{3}$ The characterization data obtained for the compound prepared were in accord with what had been published.

\section{Acknowledgements}

This work was supported by the Danish National Research Foundation.

\section{Supporting Material}

${ }^{1} \mathrm{H},{ }^{19} \mathrm{~F}$, and ${ }^{13} \mathrm{C}$ NMR spectra for compounds 4, 5, Aarhus Green and 5-carboxy-Aarhus Green.

\section{References}

1. Haugland, R. P. Handbook of Fluorescent Probes and Research Products; 9th Ed.; Molecular Probes, Inc.: Eugene, OR, 2002.

2. Lakowicz, J. R. Principles of Fluorescence Spectroscopy; 3rd ed.; Springer: New York, 2006.

3. Sun, W.-C.; Gee, K. R.; Klaubert, D. H.; Haugland, R. P. J. Org. Chem. 1997, 62, 64696475 . http://dx.doi.org/10.1021/j09706178

4. Mottram, L. F.; Boonyarattanakalin, S.; Kovel, R. E.; Peterson, B. R. Org. Lett. 2006, 8, 581 584. http://dx.doi.org/10.1021/o1052655g

5. Mchedlov-Petrossyan, N. O.; Vodolazkaya, N. A.; Gurina, Y. A.; Sun, W.-C.; Gee, K. R. J. Phys. Chem. B 2010, 114, 4551-4564. http://dx.doi.org/10.1021/jp909854s 
6. Urano, Y.; Kamiya, M.; Kanda, K.; Ueno, T.; Hirose, K.; Nagano, T. J. Am. Chem. Soc. 2005, 127, 4888-4894.

http://dx.doi.org/10.1021/ja043919h

7. Pedersen, S. K.; Holmehave, J.; Blaikie, F. H.; Gollmer, A.; Breitenbach, T.; Jensen, H. H.; Ogilby, P. R. J. Org. Chem. 2014, 79, 3079-3087.

http://dx.doi.org/10.1021/j0500219y

8. Magde, D.; Wong, R.; Seybold, P. G. Photochem. Photobiol. 2002, 75, 327-334. http://dx.doi.org/10.1562/0031-8655(2002)075<0327:FQYATR>2.0.CO;2

9. Yang, Y.; Escobedo, J. O.; Wong, A.; Schowalter, C. M.; Touchy, M. C.; Jiao, L.; Crowe, W. E.; Fronczek, F. R.; Strongin, R. M. J. Org. Chem. 2005, 70, 6907-6912. http://dx.doi.org/10.1021/jo051002a

10. Mottram, L. F.; Maddox, E.; Schwab, M.; Beaufils, F.; Peterson, B. R. Org. Lett. 2007, 9, 3741-3744. http://dx.doi.org/10.1021/o17015093

11. Mineno, T.; Ueno, T.; Urano, Y.; Kojima, H.; Nagano, T. Org. Lett. 2006, 8, 5963-5966. http://dx.doi.org/10.1021/o10623926

12. Song, L.; Hennik, E. J.; Young, I. T.; Tanke, H. J. Biophys. J. 1995, 68, 2588-2600. http://dx.doi.org/10.1016/S0006-3495(95)80442-X

13. Hedberg, C.; Dekker, F. J.; Rusch, M.; Renner, S.; Wetzel, S.; Vartak, N.; Gerding-Reimers, C.; Bon, R. S.; Bastiaens, P. I. H.; Waldmann, H. Angew. Chem. Int. Ed. 2011, 50, 98329837.

http://dx.doi.org/10.1002/anie.201102965 